\title{
Additive Manufacturing of Tooling for Refrigeration Cabinet Foaming Processes
}
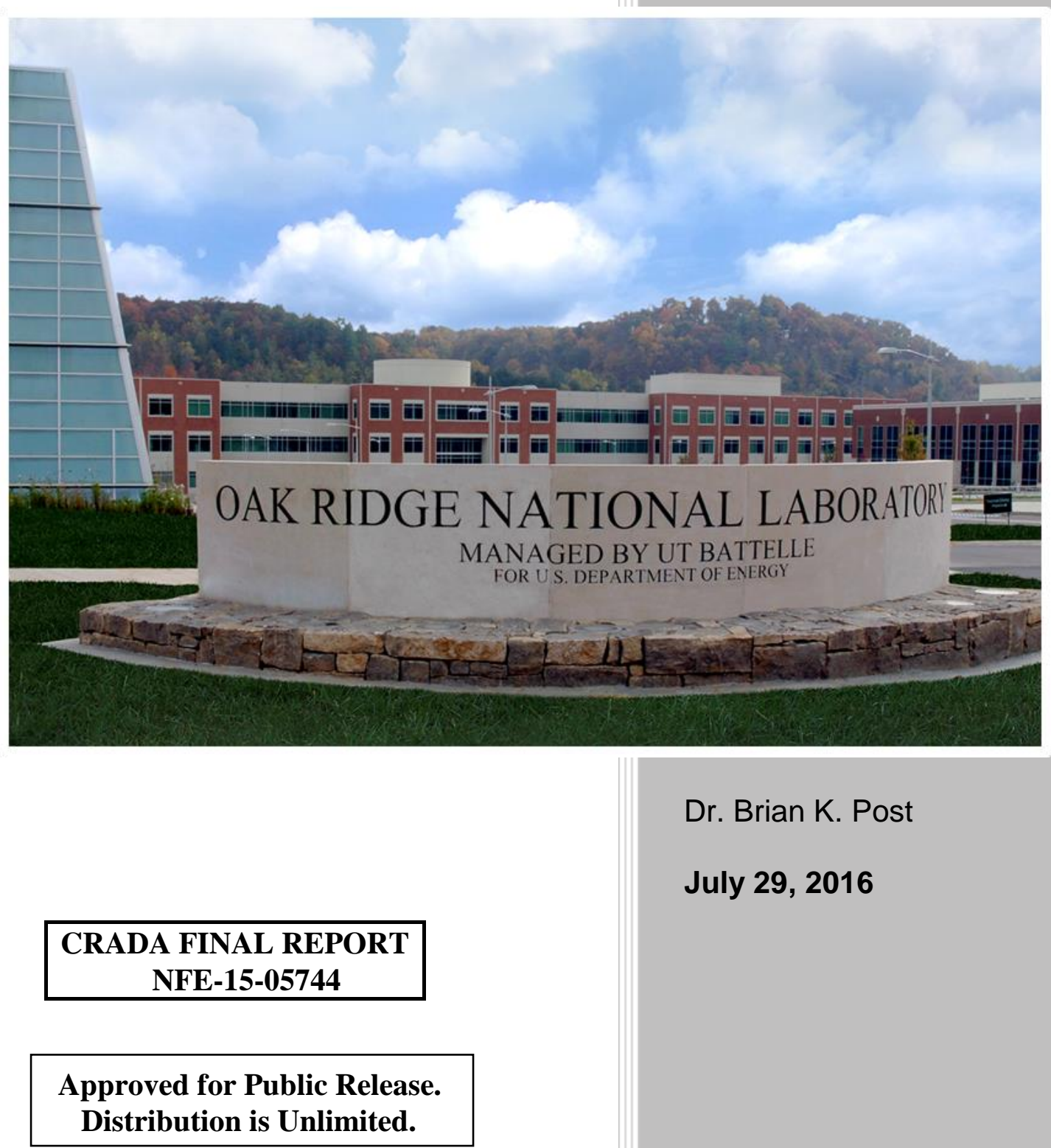

Dr. Brian K. Post

July 29, 2016 


\section{DOCUMENT AVAILABILITY}

Reports produced after January 1, 1996, are generally available free via US Department of Energy (DOE) SciTech Connect.

Website http://www.osti.gov/scitech/

Reports produced before January 1,1996, may be purchased by members of the public from the following source:

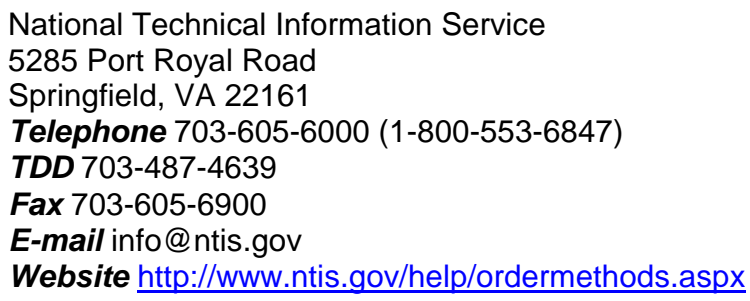

Reports are available to DOE employees, DOE contractors, Energy Technology Data Exchange representatives, and International Nuclear Information System representatives from the following source:

Office of Scientific and Technical Information

PO Box 62

Oak Ridge, TN 37831

Telephone 865-576-8401

Fax 865-576-5728

E-mail reports@osti.gov

Website http://www.osti.gov/contact.html

This report was prepared as an account of work sponsored by an agency of the United States Government. Neither the United States Government nor any agency thereof, nor any of their employees, makes any warranty, express or implied, or assumes any legal liability or responsibility for the accuracy, completeness, or usefulness of any information, apparatus, product, or process disclosed, or represents that its use would not infringe privately owned rights. Reference herein to any specific commercial product, process, or service by trade name, trademark, manufacturer, or otherwise, does not necessarily constitute or imply its endorsement, recommendation, or favoring by the United States Government or any agency thereof. The views and opinions of authors expressed herein do not necessarily state or reflect those of the United States Government or any agency thereof. 
ORNL/TM-2016/351

CRADA/ NFE-15-05744

Energy and Transportation Science Division Advanced Manufacturing Office

\title{
ADDITIVE MANUFACTURING OF TOOLING FOR REFRIGERATION CABINET FOAMING PROCESSES
}

\author{
Authors \\ Dr. Brian K. Post (ORNL) \\ David Nuttall (ORNL) \\ Michael Cukier (Whirlpool Corp.) \\ Michael Hile (Whirlpool Corp.)
}

Date Published:

July 29, 2016

Prepared by

OAK RIDGE NATIONAL LABORATORY

Oak Ridge, Tennessee 37831-6283

managed by

UT-BATTELLE, LLC

for the

US DEPARTMENT OF ENERGY

under contract DE-AC05-00OR22725 
Approved For Public Release 



\section{CONTENTS}

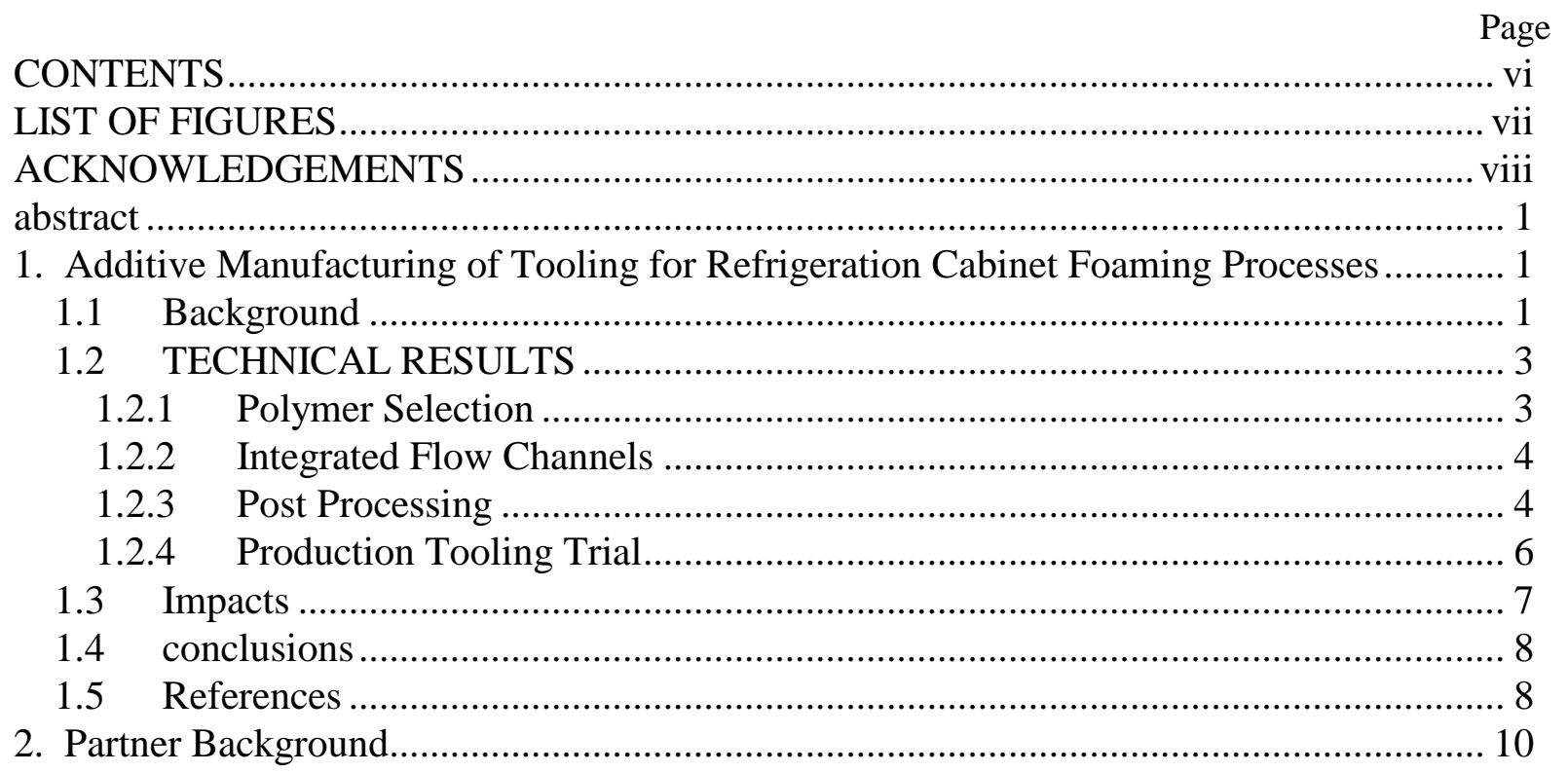




\section{LIST OF FIGURES}

Fig 1. Cabinet Foaming Mold Schematic. ......................................................................... 2

Fig 2. Target Freezer Door Foaming Mold ................................................................... 2

Fig 3. ABS Curl Bars ................................................................................................. 3

Fig 4. Printed Freezer Door Tool with Integrated Fluid Passageways .................................. 4

Fig 5. Post Processing (a) As Printed Tool (b) Subtractive Machining (c) Finished Tool ....... 5

Fig 6. Production Freezer Door Foaming Mold ................................................................ 6

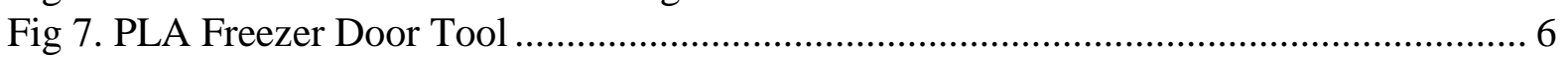

Fig 8. Thermal Distortion in the Neat PLA part ............................................................ 7

Fig 9. Manufactured Freezer Door From AM Tool .......................................................... 7 


\section{ACKNOWLEDGEMENTS}

This CRADA NFE-15-05744 was conducted as a Technical Collaboration project within the Oak Ridge National Laboratory (ORNL) Manufacturing Demonstration Facility (MDF) sponsored by the US Department of Energy Advanced Manufacturing Office (CPS Agreement Number 24761).

Opportunities for MDF technical collaborations are listed in the announcement "Manufacturing Demonstration Facility Technology Collaborations for US Manufacturers in Advanced Manufacturing and Materials Technologies" posted at http://web.ornl.gov/sci/manufacturing/docs/FBO-ORNL-MDF2013-2.pdf. The goal of technical collaborations is to engage industry partners to participate in shortterm, collaborative projects within the Manufacturing Demonstration Facility (MDF) to assess applicability and of new energy efficient manufacturing technologies. Research sponsored by the U.S. Department of Energy, Office of Energy Efficiency and Renewable Energy, Advanced Manufacturing Office, under contract DE-AC05-00OR22725 with UT-Battelle, LLC. 



\begin{abstract}
The primary objective of this project was to leverage the Big Area Additive Manufacturing (BAAM) process and materials into a long term, quick change tooling concept to drastically reduce product lead and development timelines and costs.

Current refrigeration foam molds are complicated to manufacture involving casting several aluminum parts in an approximate shape, machining components of the molds and post fitting and shimming of the parts in an articulated fixture. The total process timeline can take over 6 months. The foaming process is slower than required for production, therefore multiple fixtures, 10 or more, are required per refrigerator model. Molds are particular to a specific product configuration making mixed model assembly challenging for sequencing, mold changes or auto changeover features.

The initial goal was to create a tool leveraging the ORNL materials and additive process to build a tool in 4 to 6 weeks or less. This would provide lightweight fixture sections that could be revised in a very short time to increase equipment flexibility reduce lead times, lower the barriers to first production trials, and reduce tooling costs.
\end{abstract}

\title{
1. ADDITIVE MANUFACTURING OF TOOLING FOR REFRIGERATION CABINET FOAMING PROCESSES
}

This phase 1 technical collaboration project (NFE-15-05744) was begun on August 01, 2015 and was completed on July, 29 2016. The collaboration partner Whirlpool is a large business. This project successfully demonstrated the ability to produce low cost tooling for limited production trials for Whirlpool's refrigerator manufacturing facility's cabinet foaming line, using the Big Area Additive Manufacturing (BAAM) and Cosine Medium Area Additive Manufacturing (MAAM) processes.

\subsection{BACKGROUND}

This project stemmed from a DOE sponsored workshop on additive manufacturing (AM) applications in building technology. Advanced Manufacturing representatives from Whirlpool were in attendance and immediately identified an opportunity to use AM for tooling in their production lines. The Fortune 500 company has annual revenue of approximately $\$ 21$ billion, 100,000 employees, and more than 70 manufacturing and technology research centers around the world. The company markets Whirlpool, Maytag, KitchenAid, Jenn-Air, Amana, Gladiator GarageWorks, Inglis, Estate, Brastemp, Bauknecht, Indesit, Hotpoint and Consul. After acquiring the Maytag Corporation on March 31, 2006, the Whirlpool Corporation surpassed Electrolux to become "the largest home appliance maker in the world."[1]

The chosen application for the evaluation of AM tooling is the refrigeration cabinet foaming process. Shown schematically in Fig. 1, the mold in the foaming process supports the thermoformed liner while a shot of expanding foam is injected between the cabinet shell and the liner. 


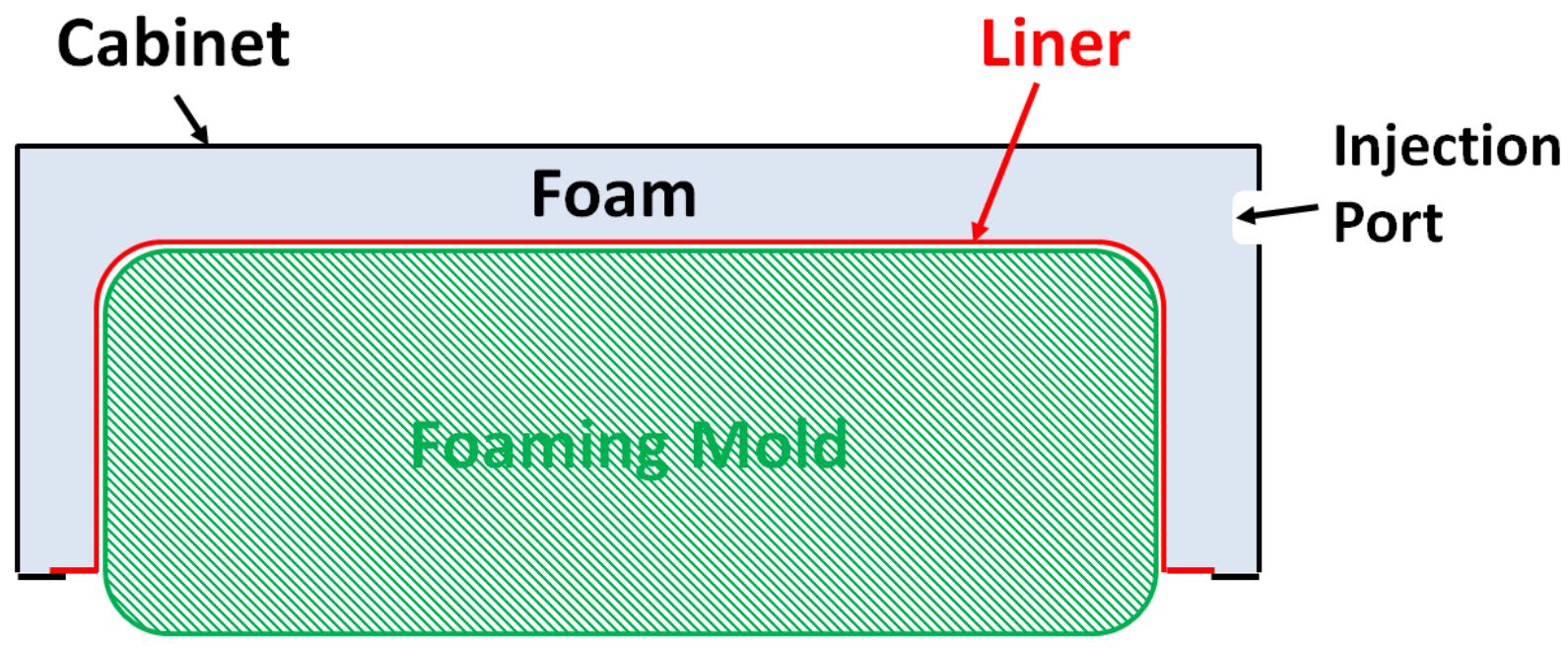

Fig 1. Cabinet Foaming Mold Schematic.

If the liner was left unsupported during this process the liner would be deformed by the pressure of the expanding foam. A full set of these foaming molds includes cabinet, drawer, and door tools to support all of the liner surfaces. The most complicated molds are those which are articulated to support the cabinet liner. The mold is inserted and the individual articulated sections expand to support the liner. In contrast the door tools are simpler, providing only a static support of the door liner. Therefore, as a test of feasibility, the freezer door tool (Fig. 2) for a new product line was selected as the target application for the CRADA project.

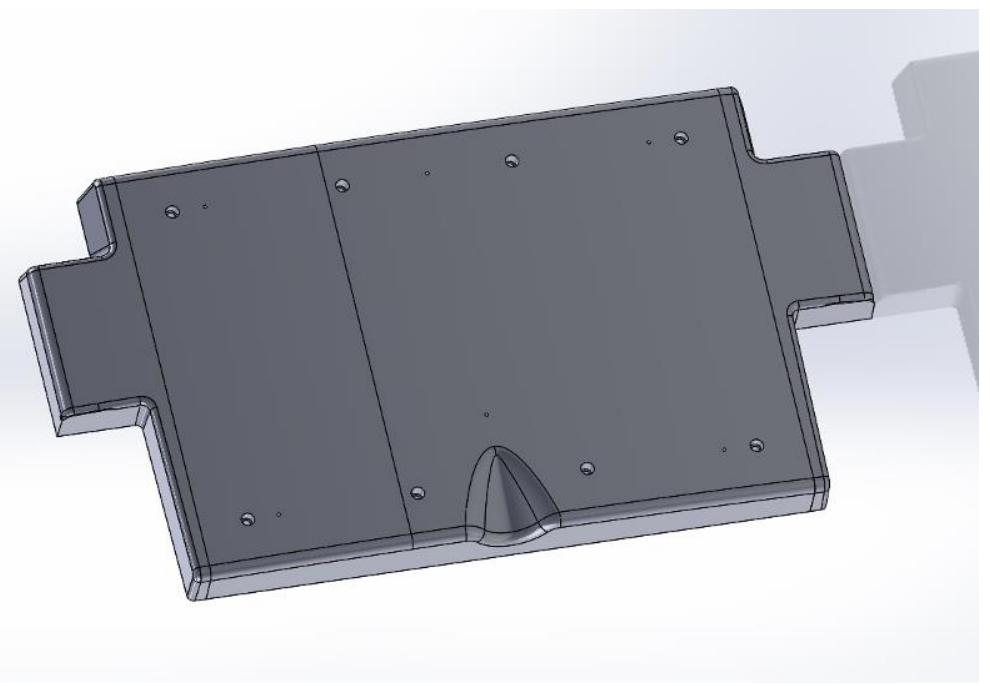

Fig 2. Target Freezer Door Foaming Mold

Current refrigeration foam molds are complicated to manufacture involving casting several aluminum parts in an approximate shape, machining components of the molds and post fitting and shimming of the parts. The total process timeline can take over 6 months. Given the extended timeline it is often necessary to purchase tooling before the product design is finalized requiring significant rework of the molds at additional cost. The foaming process is significantly slower than required for 
production, therefore multiple fixtures, 10 or more, at unit costs in excess of $\$ 50 \mathrm{~K}$, are required per refrigerator model.

Generating tooling for limited production runs quickly and economically through AM would allow Whirlpool to shortcut the product development cycle and test new products more quickly, shortening the time to market. Furthermore, if the AM tooling proves durable enough production tooling may be possible, reducing the total cost of manufacturing.

\subsection{TECHNICAL RESULTS}

The success of the tooling trial is predicated on the achievement of the stated requirements of the foaming process. These requirements are threefold: sustained pressure, elevated temperature and surface finish. In process the expanding foam can exert up to $10 \mathrm{psi}$ of pressure on the mold surface. Elevated temperatures are desired to maintain the desired viscosity of the foam to ensure complete coverage. These temperatures are generally achieved by convective heat transfer in internal mold passageways with water as the working fluid. The door tools are smaller than the cabinet tools and therefore do not typically require heating channels. Since the tool only provides support for the liner, the surface of the mold does not transfer features to the finished part. However, if a sufficiently large span of the liner is left unsupported, the liner will deform, causing surface aberrations in the finished part.

\subsubsection{Polymer Selection}

In previous work [2] the addition of carbon fiber in low weight percent has been demonstrated to significantly reduce the coefficient of thermal expansion in additively manufactured components. Fig. 3 shows two "curl bars" the upper bar is unfilled ABS material, meaning that no carbon fiber has been added, and the lower is ABS with carbon fiber in a ratio of $20 \%$ by weight.

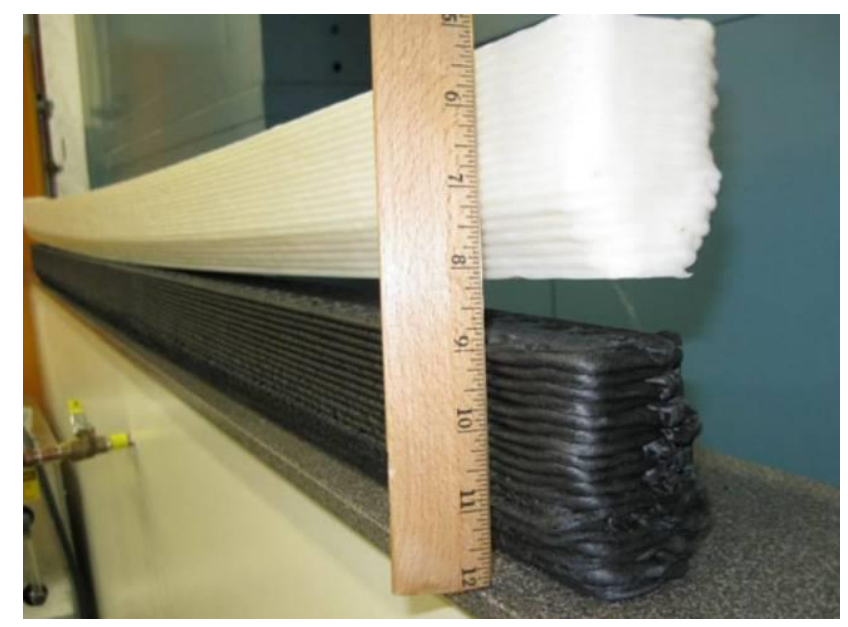

Fig 3. ABS Curl Bars

By adding carbon fiber the printed parts maintain a higher level of dimensional stability. In the direction of deposition the coefficient of thermal expansion is reduced by $90 \%$ relative to the neat material [2]. By leveraging the reduced CTE the tools can be manufactured to minimize the anisotropy of the layer by layer manufacturing process and result in near isotropic tools with CTEs approximating that of aluminum.

The addition of carbon fiber also increases the thermal conductivity of the printed material tripling it in the direction of print [2]. For active temperature control this property improves performance and 
limits the thermal gradient across the surface of the tool.

For the purposes of the tooling trials carbon fiber reinforced ABS was selected as the primary material because of these properties. A neat PLA tool was also printed using a Cosine (MAAM) machine, which to date has a limited material selection.

\subsubsection{Integrated Flow Channels}

To investigate extensibility of the results from the door tooling to more complicated cabinet tooling, which requires flow channels for thermal control, several iterations of tools were printed with internal flow passageways. An example tool is shown in Fig. 4. This tool was printed in two separate pieces and assembled to form the complete freezer door tool.

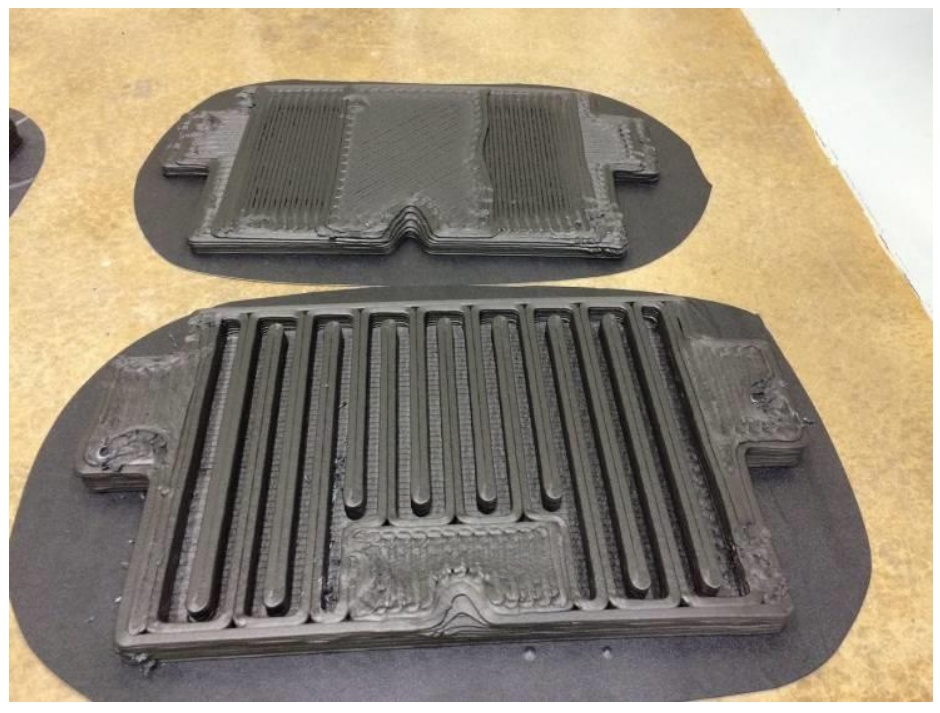

Fig 4. Printed Freezer Door Tool with Integrated Fluid Passageways

While initial results demonstrated the feasibility of printing internal passageways, the tools with internal fluid passageways were not used for the tooling trials for two reasons. Firstly, the door tools in service do not use hot/cold water for thermal control, and secondly the printed tools have varied porosity which could result in leaks over time, and a suitable sealant was not investigated.

\subsubsection{Post Processing}

In order to achieve the desired surface finish targets, the BAAM printed tools required post processing in the form of subtractive machining. The printed parts were oversized by 0.150 inches in order to place the target surface exactly $1 / 2$ bead width inside of the printed surface. The tools were then aligned on the Thermwood CNC router using a Faro X laser tracker. Subtractive machining to the desired surface finish $(0.01$ in tolerance on the surface profile) was performed using a 3/4 inch diamond coated ball end mill. The complete procedure is shown in Fig. 5. 


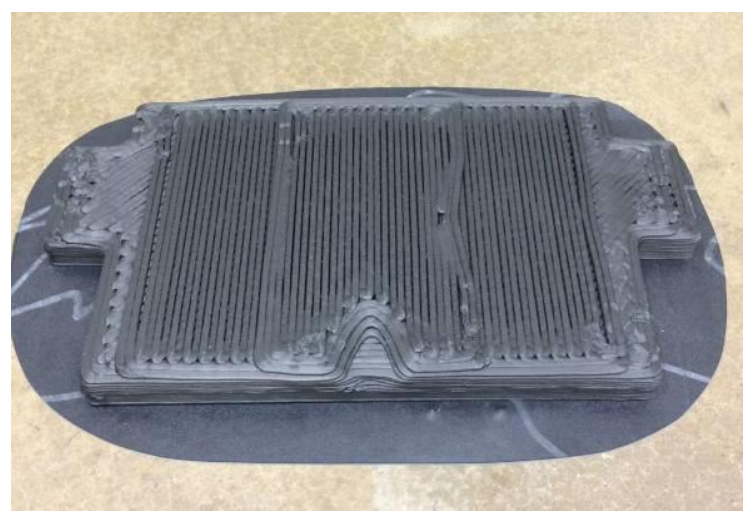

(a)

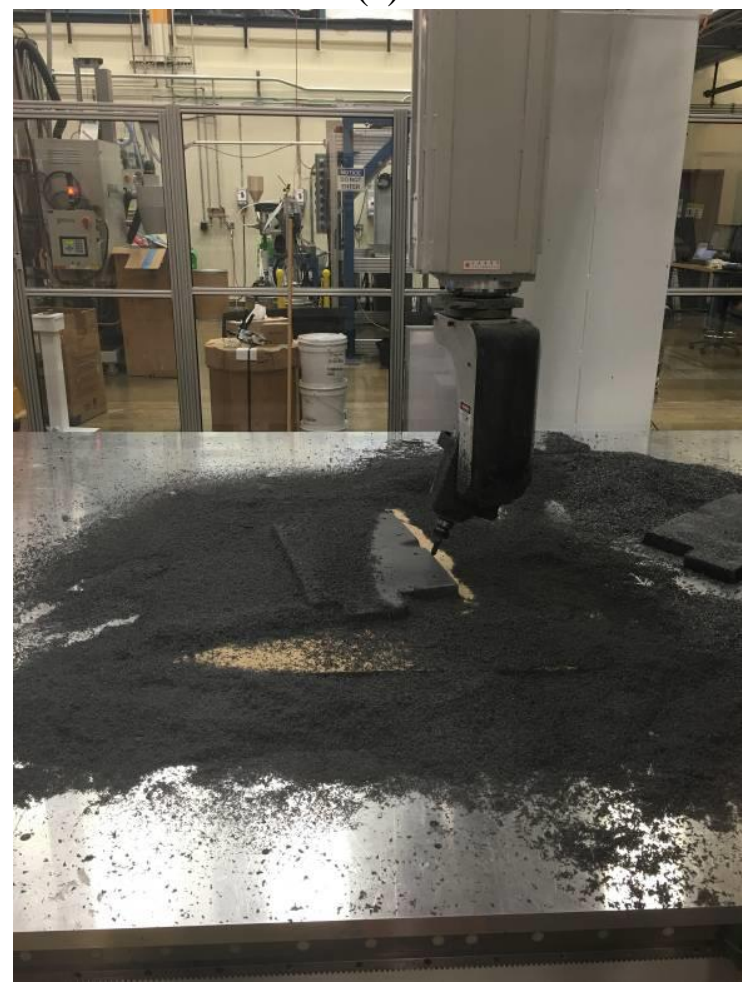

(b)

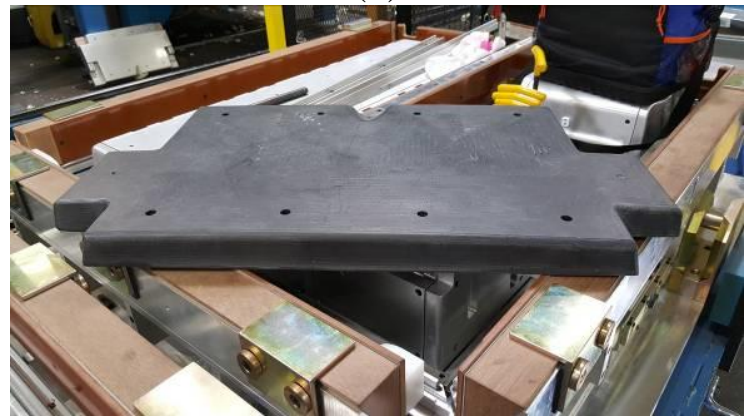

(c)

Fig 5. Post Processing (a) As Printed Tool (b) Subtractive Machining (c) Finished Tool 


\subsubsection{Production Tooling Trial}

Tooling trials were conducted at Whirlpool's Amana Iowa production facility July 1114, 2016. Three printed tools in total were used in place of the production line tools (Fig. 6) on the refrigeration foaming production line.

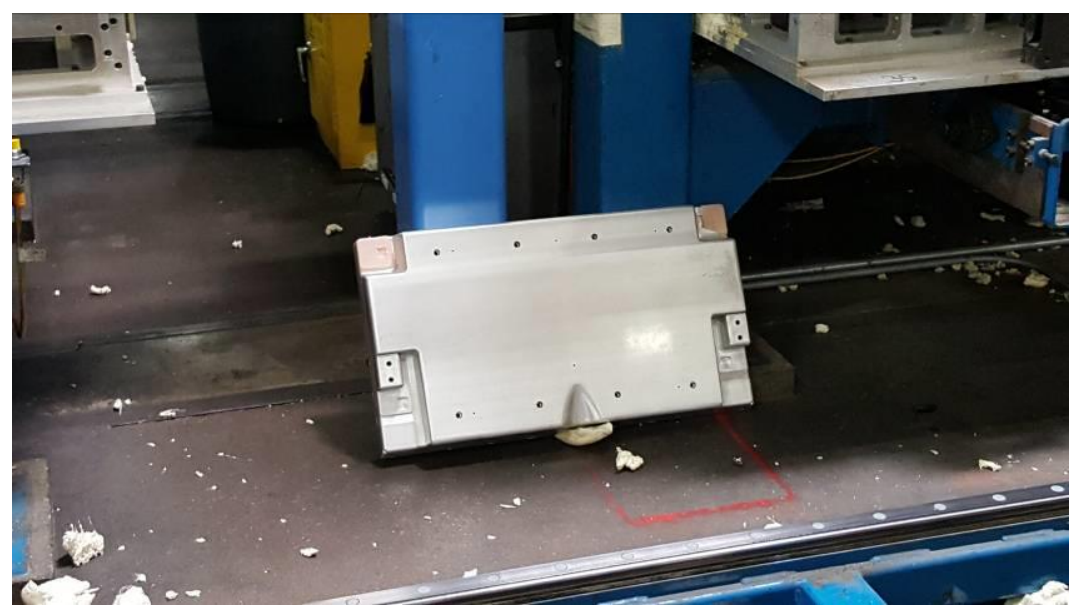

Fig 6. Production Freezer Door Foaming Mold

The three tools were as follows: two carbon fiber reinforced ABS tools $\sim 95 \%$ dense, which were printed on ORNL's BAAM machine, and subtractively post-processed, (Fig. 5C) and one PLA tool $20 \%$ dense which was printed on a Cosine Additive (MAAM) machine by ORNL and was not post machined (Fig. 7).

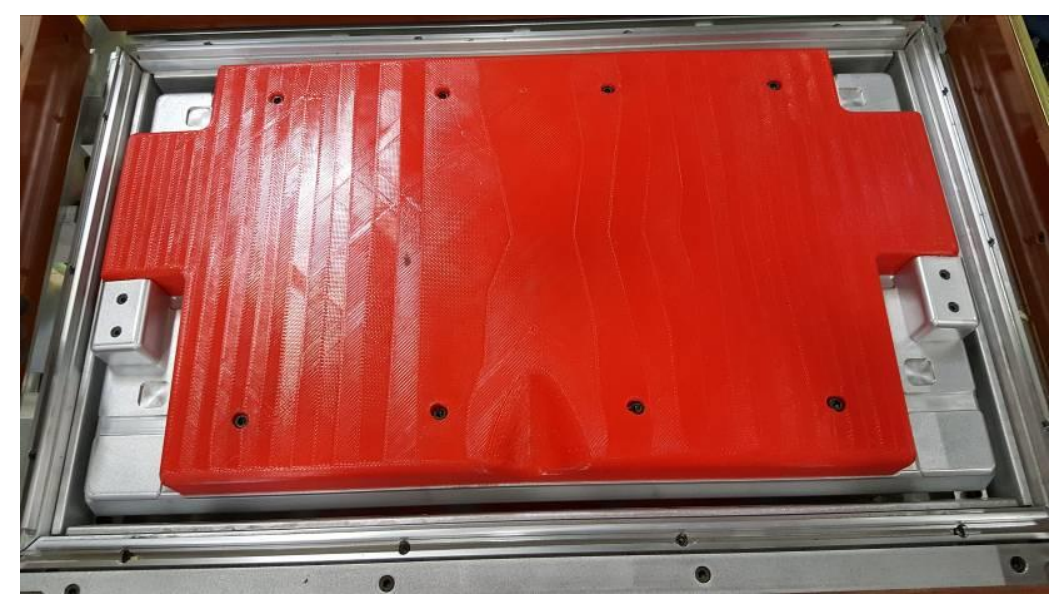

Fig 7. PLA Freezer Door Tool

Of note is the fact that thermal contraction rendered the PLA tool too small to produce dimensionally accurate parts. Fig. 8 illustrates the shrinkage by comparing the underside of the printed tool and the production aluminum tool. When biased to the top edge the bottom edge shows a $1 / 4$ inch deviation from the target dimension (equivalent to a uniform contraction of $1 / 8^{\text {th }}$ inch around the entire tool). This is an unacceptable deviation. 


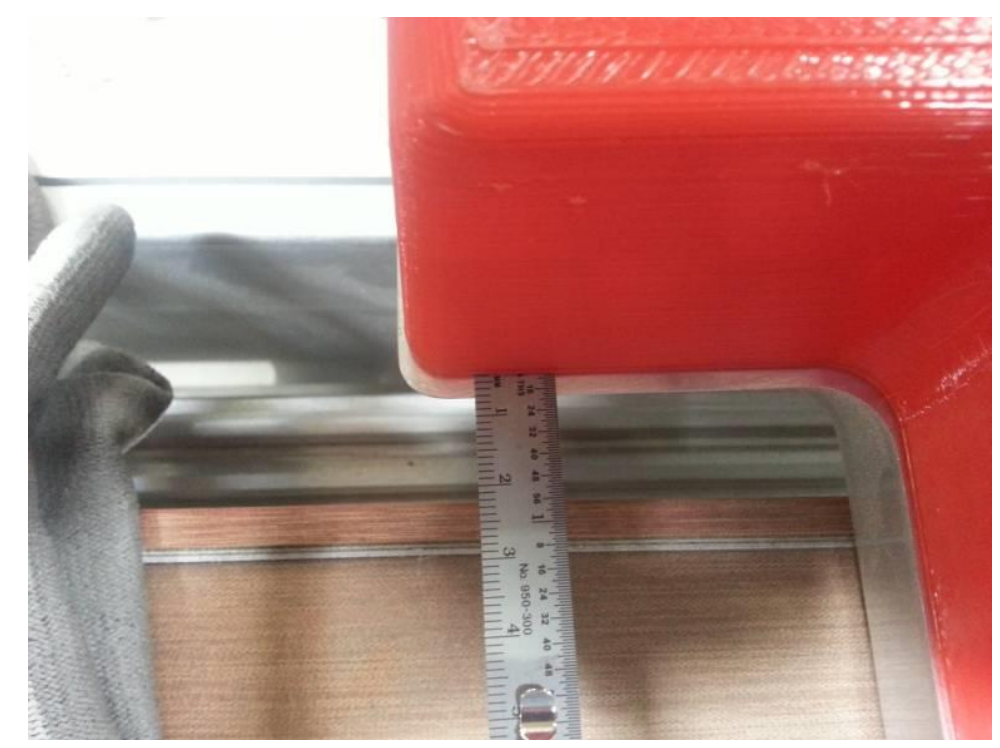

Fig 8. Thermal Distortion in the Neat PLA part

The carbon fiber reinforced ABS tools showed no net deformation.

Each tool was used to make three freezer doors on the production line, for a total of 9 doors and all were completed successfully with no apparent wear to the tools. Even the doors made with the unmachined Cosine tool showed no signs of the layer stratifications in the finished part as shown in Fig 9.

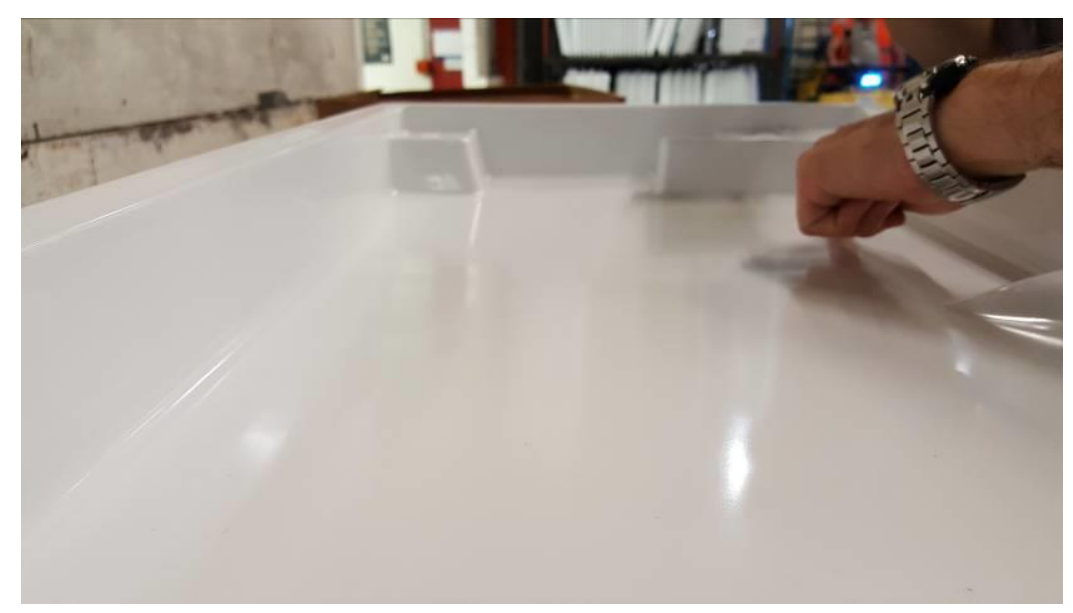

Fig 9. Manufactured Freezer Door from AM Tool

\section{$1.3 \quad$ IMPACTS}

Whirlpool is the industry leader in the manufacturing and marketing of home appliances. The results of this project have demonstrated a production capable method for developing low cost short turn tooling in as little as one day per mold set. Whirlpool recognizes this result as a disruptive impact on their business model. The large scale AM processes are directly applicable to their tooling needs and drastically improves their market competiveness 
by reducing the time to market. This process also enables quicker limited production runs of custom or small volume appliances that would have otherwise been prohibitively expensive to produce.

The current source of these tools is also sourced from foreign entities and shipped to the US production facilities. Producing the molds and tools directly at the production facility reduces the shipping costs and "on-shores" the mold production process.

With continued durability research and testing, there is a great potential that this process could be used to generate production tooling for large volume production models.

\subsection{CONCLUSIONS}

The objective of this project has been to evaluate the potential of large scale additive manufacturing to produce production tools for the Whirlpool refrigeration cabinet foaming process. Process criteria were established, a suitable material was selected for testing, flow channels for thermal control were investigated, and production tools were produced using two different AM technologies. In the end these tools were used to produce consumer grade products on the factory production line. The objectives of the Phase 1 CRADA have been achieved.

Targets for future research include a long duration tooling trial to assess the durability and dimensional stability of these tools in a production environment. Furthermore, to address the larger foam sections temperature control must be achieved requiring an investigation of porosity mitigation strategies which will enable water tight fluid passageways within a FDM printed structure. The porosity inherent in the printed structure could also be beneficial for thermoforming applications, i.e. making the liners themselves.

\subsection{REFERENCES}

1. "Whirlpool Corporation Reports Record Fourth-Quarter And Full-Year 2015 Results." New York Stock Exchange (NYSE:WHR). 2016. Web. 28 July 2016.

2. Love, Lonnie J., Vlastamil Kunc, Orlando Rios, Chad E. Duty, Amelia M. Elliott, Brian K. Post, Rachel J. Smith, and Craig A. Blue. "The Importance of Carbon Fiber to Polymer Additive Manufacturing." Journal of Materials Research J. Mater. Res. 29.17 (2014): 1893-898. Web. 


\section{PARTNER BACKGROUND}

Whirlpool is the industry leader in the manufacturing and marketing of home appliances. Whirlpool is a global company and markets Whirlpool, Maytag, KitchenAid, Jenn-Air, Amana, Brastemp, Bauknecht, Consul and other major brand names in more than 170 countries around the world.

Whirlpool is a company that creates innovative solutions and products to meet consumer needs. As a result, we have been recognized as one of the world's 100 most innovative companies by Business Week magazine and the Boston Consulting Group. Additionally, Whirlpool Corporation was ranked among the Top 20 Innovators in Consumer Products by The Patent Board and has been consistently ranked as one of the Top 20 Companies for Leaders by Hewitt Associates and Fortune magazine. 